CLINICAL STUDY

\title{
The cortisol awakening response is blunted in patients with active Cushing's disease
}

\author{
Silvia Liliana Ruiz Roa, Paula Conde Lamparelli Elias, Margaret Castro and Ayrton Custodio Moreira \\ Department of Medicine, School of Medicine of Ribeirao Preto, University of Sao Paulo, Avenida dos Bandeirantes, 3900 - Monte Alegre, \\ CEP: 14049-900 Ribeirao Preto, SP, Brazil \\ (Correspondence should be addressed to A C Moreira; Email: acmoreir@fmrp.usp.br)
}

\begin{abstract}
Introduction: Cortisol awakening response (CAR) is a rapid increase of cortisol levels within 30-45 min after awakening.

Objective: This study evaluates CAR compared with cortisol circadian rhythm in active and in remission Cushing's disease (CD).

Materials and methods: We evaluated healthy controls (HC, $n=19)$, obese $(\mathrm{OB}, n=10)$, in remission $(n=08)$, and active CD patients $(n=10)$. Salivary free cortisol (SF) was determined at 0800, 1100 , 1700,2000 , and $2300 \mathrm{~h}$ on the first day. CAR was obtained the next morning immediately upon awakening and at $15,30,45$, and 60-min post-wake up.

Results: We observed differences in SF levels throughout the day in $\mathrm{HC}, \mathrm{OB}$, and in remission $\mathrm{CD}$ (ANOVA $P=0.0001)$ but not in active $\mathrm{CD}(P=0.2)$. We demonstrated SF increment after awakening in $\mathrm{HC}, \mathrm{OB}$, and in remission $\mathrm{CD}$ (ANOVA $P=0.007$ ), with no effect of time on SF in active $\mathrm{CD}$. The relative increment of SF obtained at the peak after awakening (CARi\%) in the active CD (67 $\pm 57 \%)$ was lower than in HC $(154 \pm 107 \%), \mathrm{OB}(240 \pm 188 \%)$, and in remission CD $(186 \pm 184 \%)$ patients $(P=0.009)$. There was a negative correlation between the SF at awakening and the CARi\% in $\mathrm{HC}(r=-0.8), \mathrm{OB}$ $(r=-0.78)$, and in remission CD $(r=-0.74)$ but not in active CD $(r=-0.35 ; P=0.31)$.

Conclusion: This study originally described a blunted CAR in active CD in contrast to its presence in HC, $\mathrm{OB}$, and in remission $\mathrm{CD}$. This subtle dysfunction of the hypothalamus-pituitary-adrenal axis may represent a distinct and additional physiopathological phenomenon superimposing the dysregulated cortisol circadian rhythm in this disease.
\end{abstract}

European Journal of Endocrinology 168 657-664

\section{Introduction}

The hypothalamus-pituitary-adrenal (HPA) axis is a major endocrine system adapting the organism to environmental challenges in order to adjust predictive homeostasis. HPA is under regulatory control of circadian oscillators, resulting in 24-h rhythm of cortisol secretion from the adrenal cortex, with several secretory episodes of short duration and high amplitude. Cortisol levels steadily decline throughout the day with lowest levels during the first half of the night $(1,2)$. Circadian influences on physiological systems are mainly transmitted via the endogenous central pacemaker: the suprachiasmatic nucleus $(\mathrm{SCN})$. The circadian rhythm of the HPA axis is largely controlled by the SCN clock genes, which influences adrenocortical activity via input to the paraventricular nuclei of the hypothalamus $(3,4,5)$.

In addition to the well-described cortisol diurnal cycle, there is a distinct phenomenon termed cortisol awakening response (CAR), which is a rapid increase in cortisol levels of about $50-75 \%$ levels within 30-45 min after awakening in the morning. The CAR appears to be a phenomenon superimposing the circadian rhythm of cortisol as it adds a significant incremental effect to the linear trend of increasing cortisol concentrations in the early morning hours $(6,7)$. These data are supported by studies on continuous polysomnographical recordings and repeated blood sampling in the sleep laboratory. Post-awakening cortisol increase is linked to the process of awakening possibly through activation of memory representations about the self and orientation in time and space that have the potential to stimulate HPA axis activity (7). Both cortisol circadian rhythm and CAR are sensitive to light exposure; therefore, it is possible that the SCN-derived biological clock might be an additional important structure for the CAR $(8,9)$. Besides the classical neuroendocrine control of the adrenal cortex by the corticotropin-releasing hormone (CRH)/ACTH, projections of the SCN via autonomic nervous system determine the adrenal sensitivity to ACTH. Thus, preand post-awakening cortisol secretions are affected by 
the combination of the activity of the HPA axis and the sensitivity of the adrenal to ACTH (10).

The CAR has been studied extensively over the past two decades in healthy populations $(6,7,11,12)$. The research on CAR from a physiological perspective has improved the knowledge of this phenomenon and its putative impact on physiopathology of the HPA axis dysregulation. Indeed, altered CAR has been described, mainly in neurological diseases $(13,14)$, psychiatric disorders (15), such as depression, post-traumatic stress and alcohol dependence, among others (for details see references $(8,11)$ ), but also in hypertension (16), overweight (17), and metabolic syndrome (18). There are no studies on CAR in Cushing's syndrome, as the majority of studies have focused on basal cortisol samples during the morning hours (0745-0900 h) and loss of normal cortisol circadian rhythm but not related to awakening $(19,20)$. As CAR is considered a reliable measure for the acute reaction to awakening of the HPA axis, in the search of a new biological marker of cortisol secretion, we hypothesized that CAR study could contribute for the detection of a possible subtle dysfunction of the HPA axis in the Cushing's disease (CD). Therefore, this study aims to evaluate CAR in CD in comparison with the cortisol circadian rhythm, the well-known altered parameter of the HPA axis in this disease.

\section{Materials and methods}

\section{Subjects}

This study was approved by the Ethics Committee of the School of Medicine of Ribeirao Preto - University of Sao Paulo and, according to the requirements of the Declaration of Helsinki, written informed consent was obtained from all participants.

Eighteen patients with CD were investigated between 2009 and 2012 at the University Hospital of the School of Medicine of Ribeirao Preto, University of Sao Paulo. In addition to the clinical features of chronic hypercortisolism, the diagnosis of CD was established by the lack of circadian variation in salivary cortisol levels, urinary free cortisol (UFC), and other standard tests of pituitaryadrenal function, including plasma ACTH levels, low- and high-dose dexamethasone suppression, CRH tests, inferior petrosal sinus sampling, and image studies (20, 21). All 18 patients had ACTH-pituitary-dependent disease; in whom the diagnosis was later confirmed by transsfenoidal surgery or positive histopathology. Patients were clustered into two different groups: active CD (ten females; age $38.9 \pm 11.0$, ranging from 22 to 60 years) and CD after remission of the hypercortisolism (six females/two males; age $34.1 \pm 11.7$, ranging from 20 to 55 years). CD was considered in remission if the patient achieved undetectable postoperative serum cortisol levels $<85 \mathrm{nmol} / \mathrm{l}(3.0 \mu \mathrm{g} / \mathrm{dl})$ within $1-14$ days after surgery $(22,23)$. Mean time of late biochemical remission at the study date was $57.3 \pm 50.5$ months. Patients were not taking medical therapy, were not submitted to radiotherapy, and did not show hypopituitarism. In addition, they also presented suppressed salivary cortisol levels after $1 \mathrm{mg}$ dexamethasone test.

Moreover, we also studied ten obese women (OB) presenting essential hypertension, idiopathic hirsutism, or menstrual disorders (age 34.3 \pm 10.2 , ranging from 22 to 56 years). Some patients were on medical treatment for hypertension, diabetes, and dyslipidemia, and two patients were on estrogen treatment. These obese controls had normal salivary cortisol circadian variation and suppressed salivary cortisol levels after $1 \mathrm{mg}$ dexamethasone test. Furthermore, we studied 19 normal, no obese healthy volunteers (13 females/six males, age $34.9 \pm 12.0$, ranging from 22 to 63 years). Exclusion criteria from healthy volunteers were previous use of any drugs, including glucocorticoids, and no history of acute or chronic cardiopulmonary, hepatic, renal, neuropsychiatric illness, or sleep disturbance. In addition, none of them were pregnant or a night-shift worker.

\section{Methods}

Cortisol circadian rhythm and CAR assessed by salivary cortisol Salivary free cortisol (SF) samples were collected by Salivette sampling devices (Salivette; Sarstedt, Nuembrecht, Germany) on two consecutive weekdays after instruction by one of the investigators. Participants were asked not to use alcohol or work out two days before the study.

Samples of healthy volunteers were collected at home while samples from CD and obese patients were obtained inpatient at University Hospital. Circadian rhythm was determined at 0800, 1100, 1700, 2000, and $2300 \mathrm{~h}$ on the first day. CAR was obtained in the next morning immediately upon awakening and at 15, 30, 45, and 60 min post-wake up. Moreover, specific instructions were given to all participants: they should note the time they went to the bed, the duration of sleep, the wake-up time, and also register the time of food ingestion and the time of each sample collection. Any deviations from the recommended schedule should also be noted. Participants were asked not to eat or drink anything, brush their teeth, or smoke $1 \mathrm{~h}$ before collection of the samples. The salivary samples were stored at $-20{ }^{\circ} \mathrm{C}$ until analysis. Salivary cortisol measurements were performed as previously described by RIA method on $25 \mu \mathrm{l}$ samples of saliva without prior extraction or chromatography (24). All samples obtained from each subject were analyzed in duplicate in the same assay.

UFC was measured during three consecutive days by liquid chromatography associated with tandem mass spectrometry (LC-MS/MS - normal range of $3-43 \mu \mathrm{g} / 24 \mathrm{~h})(25)$ in active CD. The mean of the three measurements was used to perform statistical analysis. 
Sleep quality test To evaluate sleep quality, we used the Pittsburgh Sleep Quality Index (PSQI). This index is a self-rated questionnaire that assesses sleep quality and disturbances over a 1-month time interval. Nineteen individual items generate seven 'component' scores: subjective sleep quality, sleep latency, sleep duration, habitual sleep efficiency, sleep disturbances, use of sleeping medication, and daytime dysfunction. The sum of scores for these seven components yields one global score. A global PSQI score $>5$ yielded a diagnostic sensitivity of $89.6 \%$ and specificity of $86.5 \%$ in distinguishing good and poor sleepers (26).

\section{Statistical analysis}

Data are expressed as mean \pm s.D. To define the normal circadian salivary cortisol rhythm, we adopted the cutoff value of $2300 \mathrm{~h}$ salivary cortisol levels of $9.8 \mathrm{nmol} / \mathrm{l}$ (or $350 \mathrm{ng} / \mathrm{dl}$ ) by RIA (27).

To obtain indices for CAR, the absolute increment was obtained by salivary cortisol at the peak after awakening minus salivary cortisol at awakening (zero time). Relative increment was obtained by the absolute increment divided by salivary cortisol at awakening (zero time) (8). A salivary cortisol-relative increment of $50 \%$ within the first $45 \mathrm{~min}$ after awakening was considered as CAR, according to a previous study in normal subjects (6). Kruskal-Wallis ANOVA was performed for multiple comparisons among different groups and the Dunn's multiple comparison test was used as a post hoc test. The Wilcoxon-Mann-Whitney $U$ test was used when appropriate. Receiver-operating characteristic (ROC) curves were generated to detect the best CAR-relative increment values associated with discrimination between active $\mathrm{CD}$ and a group comprising obese patients and healthy subjects. Data analyses were carried out with the statistical package GraphPad PRISM 4.0 (GraphPad software, Inc., 2003, La Jolla, CA, USA). Significance was assumed when $P<0.05$.

\section{Results}

There were no differences in age and gender among active $\mathrm{CD}, \mathrm{CD}$ after remission of the hypercortisolism (in remission $\mathrm{CD})$, obese patients $(\mathrm{OB})$, and healthy control (HC) groups. Regarding clinical findings, the BMI $\left(\mathrm{kg} / \mathrm{m}^{2}\right)$ in the OB group $(40.7 \pm 4.7)$ was the highest compared with all other groups $(P<0.01)$. Active CD group BMI $(34.5 \pm 4.5)$ was higher than in remission $\mathrm{CD}(26.4 \pm 4.5 ; \quad P=0.004)$ and $\mathrm{HC}(23.6 \pm 3.3$; $P=0.0001)$ groups; there was no difference in BMI between in remission $\mathrm{CD}$ and $\mathrm{HC}$ groups $(P=0.14)$. Regarding the mean blood pressure (BP; $\mathrm{mmHg}$ ) levels, HC group $(86 \pm 2)$ showed the lowest level $(P=0.003)$ compared with in remission CD $(95 \pm 7)$, obese $(103 \pm 3.5)$, and active CD (100 \pm 3$)$; no difference in mean $\mathrm{BP}$ was observed among active $\mathrm{CD}$, in remission $\mathrm{CD}$, and $\mathrm{OB}$ groups. There was no difference in years of education among active CD $(13.1 \pm 2.6)$, in remission $\mathrm{CD}(13.1 \pm 2.1)$ and $\mathrm{OB}(12.7 \pm 2.7)$ groups. However, the HC group had the highest level of education (18.3 \pm 3.5 years of education).

All subjects had at least four meals per day. There were no differences in the mealtimes among all groups, but the HC group had dinner $1 \mathrm{~h}$ later. All groups went to bed at similar times, from $2300 \mathrm{~h}$ to midnight and were woken up at 0500 to $0615 \mathrm{~h}$. There were no differences regarding the duration of sleep among all groups ( $6-8 \mathrm{~h}$ of sleep). A global PSQI score $<5$ were observed in normal controls (4.3 \pm 2.0 ; median of 4.0, range 2-10) and in remission $\mathrm{CD}(3.9 \pm 2.8$; median of 3.0, range 1-10) indicating good sleepers. However, PSQI scores in active CD $(8.2 \pm 3.9$, median of 8.5 , range 3-14) and $\mathrm{OB}(7.5 \pm 3.9$, median of 7.0, range 3-14) groups were higher than 5, indicating poor sleepers. We observed no difference in the global quality of sleep between $\mathrm{HC}$ and in remission CD patients and both groups showed lower PSQI scores than $\mathrm{OB}$ and active $C D$ patients $(P=0.02)$. There was no difference in PSQI scores between $\mathrm{OB}$ and active $\mathrm{CD}$ groups. No abnormal event occurred during the experimental protocol in any group.

\section{Salivary cortisol circadian rhythm and CAR}

The mean $( \pm$ s.D. ) values of salivary cortisol at 0800 , $1100,1700,2000$, and $2300 \mathrm{~h}$ in $\mathrm{HC}, \mathrm{OB}$, in remission $\mathrm{CD}$, and active CD groups are shown in Table 1. Figure 1 shows individual salivary cortisol values obtained at 0800 and $2300 \mathrm{~h}$ for each group. ANOVA demonstrated significant differences in salivary cortisol levels among 0800, 1100, 1700, 2000, and $2300 \mathrm{~h}$ for HC, $\mathrm{OB}$, and in remission $\mathrm{CD}(P=0.0001)$ but not in active $\mathrm{CD}(P=0.2)$. The salivary cortisol levels of patients with active CD were significantly elevated at 0800,1100 , 1700,2000 , and $2300 \mathrm{~h}$ compared with all other groups $(P=0.01)$; however, there were no differences

Table 1 Salivary cortisol circadian profile in healthy controls, obese, in remission Cushing's disease (CD), and active CD patients. Cortisol concentrations in $\mathrm{nmol} / /$; values in $\mathrm{X} \pm$ s.D.

\begin{tabular}{|c|c|c|c|c|c|}
\hline Groups & $0800 \mathrm{~h}$ & $1100 \mathrm{~h}$ & $1700 \mathrm{~h}$ & $2000 \mathrm{~h}$ & $2300 \mathrm{~h}$ \\
\hline Healthy controls $(n=19)$ & $49.5 \pm 21.7$ & $23.8 \pm 14.1$ & $19.1 \pm 9.5$ & $12.0 \pm 8.2$ & $5.4 \pm 3.1$ \\
\hline Obese $(n=10)$ & $38.9 \pm 14.1$ & $20.9 \pm 9.5$ & $19.4 \pm 14.9$ & $11.0 \pm 5.7$ & $7.4 \pm 5.0$ \\
\hline Remission CD $(n=8)$ & $26.9 \pm 5.4$ & $17.2 \pm 10.0$ & $11.6 \pm 5.2$ & $12.2 \pm 8.7$ & $10.0 \pm 6.9$ \\
\hline Active CD $(n=10)$ & $70.8 \pm 27.7$ & $57.4 \pm 22.8$ & $49.3 \pm 16.7$ & $58.4 \pm 22.1$ & $49.1 \pm 23.3$ \\
\hline
\end{tabular}




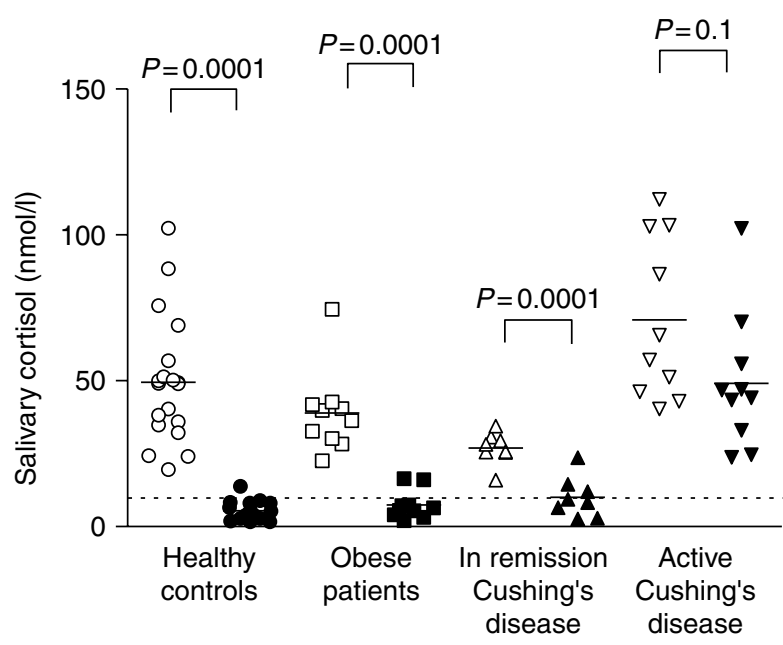

Figure 1 Individual data for salivary cortisol values obtained at $0800 \mathrm{~h}$ (open symbols) and $2300 \mathrm{~h}$ (closed symbols) for healthy controls (open circle), obese (open square), in remission Cushing's disease (CD) (open triangle), and active CD patients (open down triangle). The horizontal dotted line represents $\mathrm{Cl} 95 \%$ salivary cortisol cutoff $(9.8 \mathrm{nmol} / \mathrm{l})$ used to discriminate Cushing's syndrome from obese patients.

among the $\mathrm{HC}, \mathrm{OB}$, and in remission $\mathrm{CD}$ groups. In addition, each patient from the active $\mathrm{CD}$ group had elevated UFC, individual values ranging from 48.1 to 235.7 ( $\mathrm{X} \pm$ s.D.; $120 \pm 76 \mu \mathrm{g} / 24 \mathrm{~h}$ ).

Considering the cutoff values of salivary cortisol of $9.8 \mathrm{nmol} / \mathrm{l}(350 \mathrm{ng} / \mathrm{dl})$, normal cortisol circadian rhythm was characterized in $95 \%$ of the healthy subjects, $80 \%$ of $\mathrm{OB}$ patients, $62 \%$ of remission $\mathrm{CD}$ patients, and in none of the active $\mathrm{CD}$ patients.

Table 2 shows the mean ( \pm s.D. $)$ values of salivary cortisol in $\mathrm{HC}, \mathrm{OB}$, in remission $\mathrm{CD}$, and active $\mathrm{CD}$ groups at awaking (time 0 ) and after 15, 30, 45, and 60 min, as well as the absolute and relative increment of CAR values. ANOVA revealed a significant main effect of time on salivary cortisol in HC $(P=0.0001)$, OB $(P=0.001)$, and in remission CD $(P=0.007)$, with a significant increment at 30 and $45 \mathrm{~min}$ after awakening. However, in active $\mathrm{CD}$, we observed no effect of time on salivary cortisol values post-awakening $(P=0.76$, Fig. $2 \mathrm{~A})$.

The absolute increment of salivary cortisol obtained at the peak after awakening was not different among all groups. There was also no difference in the relative increment of salivary cortisol peak among HC (154士 $107 \%)$, OB $(240 \pm 188 \%)$, and in remission CD $(186 \pm 184 \%)$ patients. However, the relative increment of salivary cortisol in the active CD $(67 \pm 57 \%)$ was lower than $\mathrm{HC}(P=0.009)$, $\mathrm{OB} \quad(P=0.01)$, and in remission $\mathrm{CD}(P=0.01)$ patients. Figure $2 \mathrm{~B}$ shows the mean values in the percentage of relative increment of salivary cortisol after awakening at 15, 30, 45, and $60 \mathrm{~min}$ in all studied groups. CAR was present in HC, obese patients, and in remission CD groups and blunted in active $\mathrm{CD}$ as a group. However, considering the individual salivary cortisol-relative increment of $50 \%$ after awakening, CAR was observed in 95, 90, 88, and $50 \%$ of $\mathrm{HC}$, obese, in remission $\mathrm{CD}$, and active $\mathrm{CD}$ patients respectively. Using the ROC curve, the sensitivity and the specificity of the CAR-relative increment of salivary cortisol in identifying active CD compared with healthy subjects and obese patients were $80 \%$ when the salivary cortisol-relative increment of $77 \%$ was applied.

There was a negative correlation between the salivary cortisol at zero time (at awakening) and the relative increment of salivary cortisol at the peak after awakening in healthy subjects $(r=-0.8 ; P<0.0001)$, $\mathrm{OB}(r=-0.78 ; P=0.007)$, and in remission $\mathrm{CD}$ $(r=-0.74 ; P=0.04)$ but not in active $\mathrm{CD}(r=-0.35$, NS). Figure 3 shows the correlation between salivary cortisol at awakening and the relative increment of salivary cortisol at the peak after awakening in all subjects $(r=-0.73 ; P=0.0001)$. There was a trend of association between the relative increment of salivary cortisol at the peak after awakening and the $2300 \mathrm{~h}$ salivary cortisol levels $(r=-0.25 ; P=0.07)$ as well as with the duration of symptoms $(r=-0.55 ; P=0.1)$. We observed in active CD neither correlation between the relative increment of salivary cortisol at the peak after awakening and the mean concentration of salivary cortisol during the day nor the UFC $(r=0.11$ and $r=-0.13$ respectively). There was a negative correlation between the PSQI score and the relative increment of salivary cortisol at the peak after awakening $(r=-0.4 ; P=0.04)$.

\section{Discussion}

In this study, CAR was evaluated, for the first time, in patients with active CD. We observed no effect of time on salivary cortisol values post-awakening in these

Table 2 Salivary cortisol awakening response in healthy controls, obese, in remission Cushing's disease (CD), and active CD patients. Cortisol concentrations in nmol//; values in X \pm s.D.; absolute increment means salivary cortisol at the peak after awakening minus salivary cortisol at awakening (zero time). Relative increment means the absolute increment divided by salivary cortisol at awakening (zero time).

\begin{tabular}{|c|c|c|c|c|c|c|c|}
\hline Groups & $0 \mathrm{~min}$ & $15 \mathrm{~min}$ & $30 \mathrm{~min}$ & $45 \mathrm{~min}$ & $60 \mathrm{~min}$ & $\begin{array}{l}\text { Absolute } \\
\text { increment }\end{array}$ & $\begin{array}{c}\text { Relative } \\
\text { increment (\%) }\end{array}$ \\
\hline Healthy controls & $31.7 \pm 13.0$ & $49.3 \pm 17.9$ & $58.3 \pm 19.4$ & $62.6 \pm 20.2$ & $57.7 \pm 20.2$ & $39.1 \pm 17.4$ & $154 \pm 107$ \\
\hline Obese & $25.7 \pm 12.3$ & $43.2 \pm 21.3$ & $61.3 \pm 17.1$ & $61.6 \pm 25.8$ & $48.3 \pm 14.3$ & $45.6 \pm 22.9$ & $240 \pm 188$ \\
\hline Remission CD & $21.3 \pm 8.1$ & $34.9 \pm 13.2$ & $48.0 \pm 17.3$ & $42.1 \pm 11.4$ & $43.7 \pm 7.8$ & $29.8 \pm 14.9$ & $186 \pm 184$ \\
\hline Active CD & $48.5 \pm 21.6$ & $62.1 \pm 29.0$ & $66.4 \pm 33.5$ & $67.5 \pm 36.8$ & $59.1 \pm 30.1$ & $28.0 \pm 25.8$ & $67 \pm 57$ \\
\hline
\end{tabular}



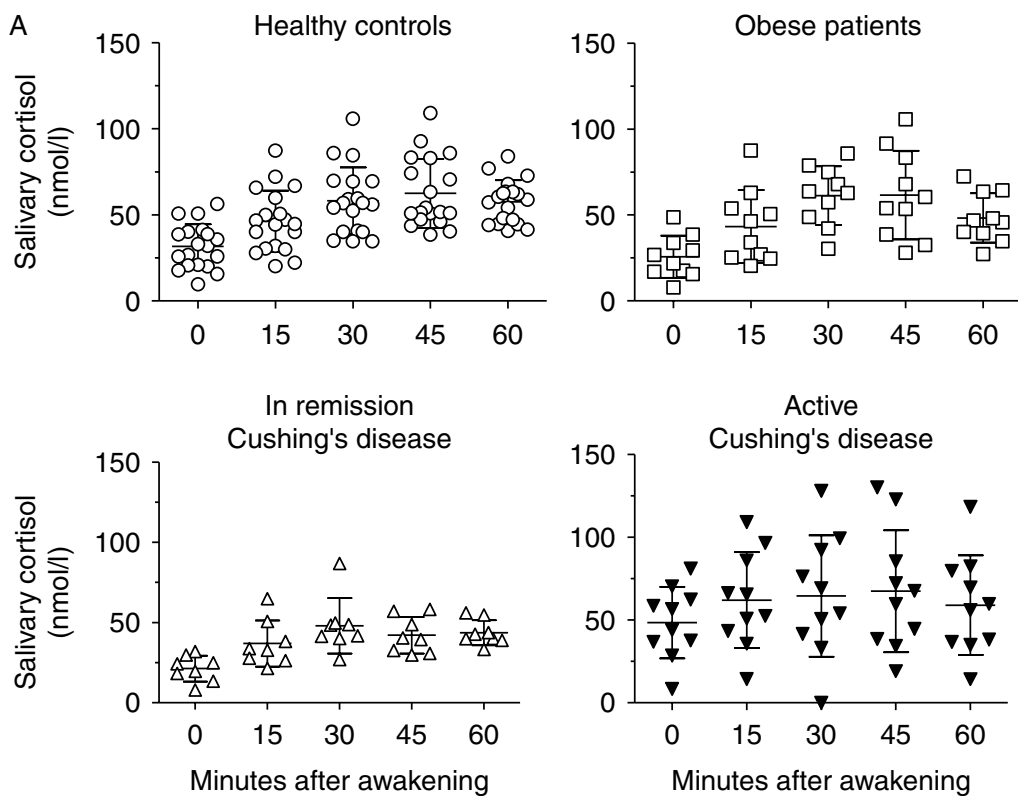

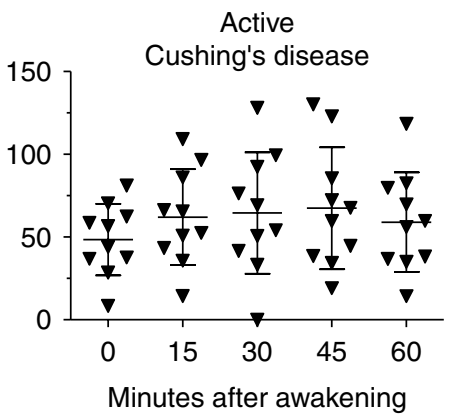

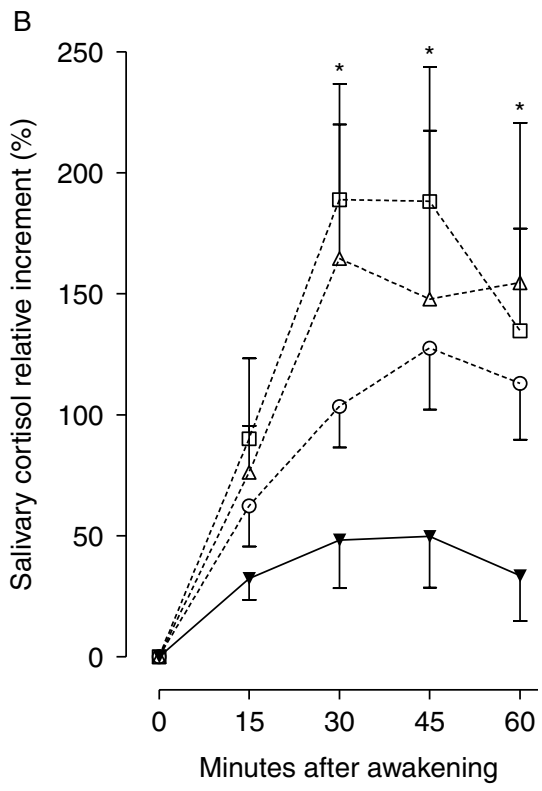

Figure 2 (A) Individual salivary cortisol levels at awakening (0), 15, 30, 45, and 60 min after awakening in healthy controls (open circle), obese (open square), in remission Cushing's disease (CD) (open triangle), and in active CD patients (closed down triangle). Healthy controls, obese, and in remission CD patients show significant salivary cortisol increment at 30 and 45 min after awakening $(P<0.01)$. No effect of time on salivary cortisol values post-awakening was observed in active $\mathrm{CD}(P=0.76)$. (B) Mean ( \pm s.E.M.) percentage increment of salivary cortisol after morning awakening. ${ }^{\star} P<0.05$ between active $\mathrm{CD}$ patients and the other three groups. No difference was observed among $\mathrm{HC}, \mathrm{OB}$, and in remission $\mathrm{CD}$.

patients, in contrast to the presence of CAR in HC, obese patients, and in remission $\mathrm{CD}$ patients. In addition, the relative increment of salivary cortisol at the peak after awakening was negatively correlated with salivary cortisol at awakening in all subjects. Our results suggest that the blunted CAR in active CD patients would be related to the hypercortisolism at awakening.

The introduction of salivary cortisol assessment, both in inpatient and outpatient settings, has allowed the study of HPA axis response patterns without the need of repeated blood samples $(19,20,28)$. In this study, we evaluated the salivary cortisol levels of patients with active $\mathrm{CD}$ compared with $\mathrm{HC}$, obese, and in remission CD groups. As expected, active CD patients showed elevated cortisol levels throughout the day, characterizing a disrupted cortisol circadian rhythm, independently of the adopted criteria.

CAR represents a distinct phenomenon of the HPA axis regulation and has never been described in active or in remission CD. We demonstrated that CAR is blunted in this series of active CD patients, as there was no effect of time on salivary cortisol values post-awakening, whereas it was present in $\mathrm{CD}$ after remission as well as in obese patients and HC. It is important to point out the novelty of this data; however, further CAR studies need to be performed in a large number of active CD patients in order to confirm our data. In this study, we evaluated three different control groups as altered CAR has been associated with demographic aspects, such as: age and gender, BMI, and food ingestion; menstrual cycle phase, oral contraceptive intake, and smoking habit; physical factors; psychological or psychiatric diseases; and sleeprelated factors including waking time, sleep duration, and sleep quality (11).

Obesity and metabolic syndrome share several clinical features with Cushing's syndrome (18). Therefore, to avoid potential influences of metabolic syndrome

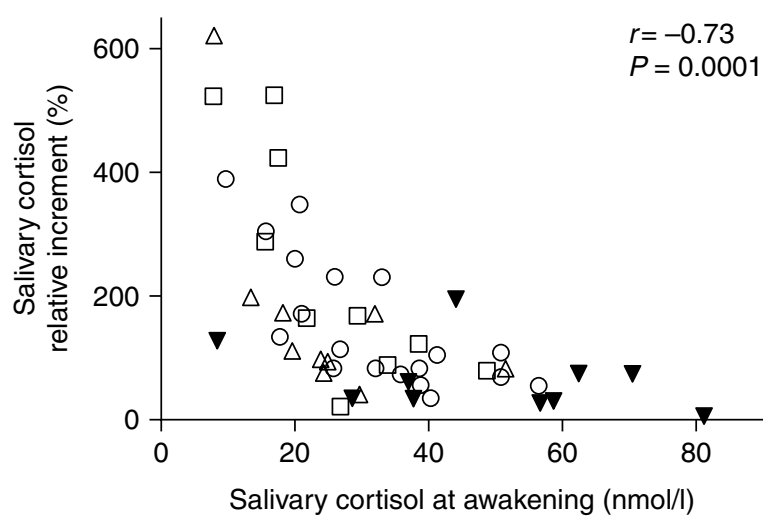

Figure 3 Pooled data obtained from the correlation between salivary cortisol at zero time (at awakening) and relative increment of salivary cortisol at the peak after awakening in healthy controls (open circle), obese (open square), in remission Cushing's disease (CD) (open triangle), and active CD (closed down triangle). Each group showed a negative correlation between the salivary cortisol at awakening and the relative increment at the peak: healthy subjects $(r=-0.8, P<0.0001)$, obese $(r=-0.78, P=0.007)$, and in remission $\operatorname{CD}(r=-0.74, P=0.04)$, but active CD $(r=-0.35, \mathrm{NS})$. 
components in salivary cortisol on circadian rhythm and awakening response evaluation, we included patients with obesity, hypertension, and menstrual disorders. We found that although this group showed BMI and BP similar to the active CD patients, they showed normal cortisol rhythm and CAR. Our data are in agreement with that recently described by DeSantis et al. (29), demonstrating no association of metabolic syndrome components with the magnitude of CAR.

A recent study suggested that higher educational level was associated with greater cortisol levels postawakening (30). Although the healthy subjects of our study showed the highest level of education compared with all other groups, they did not show greater CAR.

Sleep duration and disturbance were self-reported by subjects using a well-validated scale (26). The sleep schedule and sleep duration were similar among all groups, although the PSQI sleep quality indicated that active $\mathrm{CD}$ and obese patients were poor sleepers, with no difference in PSQI scores between both groups. Therefore, it is unlikely that the quality of sleep would be responsible for the blunted CAR observed in active $\mathrm{CD}$ patients. Alteration of parameters of sleep, such as selfreported short sleep duration in an English cohort, has been associated with both increased CAR and shallow slope in diurnal cortisol secretion (31). However, in agreement with our data, another previous study in healthy women showed that the morning CAR after disturbed sleep did not differ from the morning CAR following undisturbed sleep (32). Altogether, these data indicate that sleep disturbance per se might not have a significant influence on CAR.

Other parameters directly related to the dysregulation of the HPA axis status would be responsible for the blunted CAR observed in active CD patients. The most recommended parameters to characterize the CAR are the first waking sample (zero time) and the relative increment, which means the relative change in cortisol secretion following awakening (10). We observed a negative correlation between the salivary cortisol at awakening and the relative increment of salivary cortisol at the peak after awakening in healthy subjects, obese, and in remission $\mathrm{CD}$ patients, indicating that high levels of awakening cortisol are associated with attenuated CAR in these three control groups. Our data in controls are in agreement with previous studies also performed in healthy individuals $(7,33,34)$. In addition, we expanded this knowledge to obese and in remission CD patients, in which groups a similar negative correlation was observed between the salivary cortisol at awakening and its relative increment at the peak after awakening. Moreover, we described for the first time that this relationship was lost in active CD patients, indicating clearly that the hypercortisolism at awakening influences the relative amplitude of CAR.

It is interesting to note that pre- and post-awakening cortisol secretions are under different regulatory controllers. Cortisol at zero time represents the immediate pre-awakening period, which seems to be associated with decreased adrenal sensitivity to ACTH $(10,11)$. Crucial brain regions implicated in this process include the hippocampus (35), which plays a major role in inhibiting the HPA axis before awakening $(36,37,38)$. The zero time awakening salivary cortisol is elevated in CD patients; this phenomenon could mask CAR. However, we cannot rule out that the blunted CAR could be due to the reduction in SCN-mediated 'fine tuning' of adrenal sensitivity as the pre-awakening hippocampus activation might be impaired in active CD. Indeed, a reduced hippocampal volume in patients with Cushing's syndrome and in other conditions associated with hypercortisolism has been described $(39,40)$. In addition, these changes are reversible, at least in part, following treatment of CD (41).

Another possible explanation for the blunted CAR in active $\mathrm{CD}$ patients would be the severity of hypercortisolism evaluated by the mean concentration of salivary cortisol and UFC. This possibility cannot be supported by our data. On the other hand, we observed a trend of association between more attenuated CAR and the duration of symptoms in active $\mathrm{CD}$ and also with $2300 \mathrm{~h}$ salivary cortisol levels. Further studies with large series of CD patients are necessary to completely rule out the role of sustained hypercortisolism in blunted CAR observed in active CD patients. Moreover, other studies are also important to increase the number of patients in order to establish the putative use of CAR as a biomarker of hypercortisolism in the differential diagnosis of Cushing's syndrome. Even so, the sensitivity and specificity of a single outpatient $2300 \mathrm{~h}$ salivary cortisol level above the 90th percentile of the obese patients' values $(93.3 \% / 93.3 \%)(19,20)$ are superior to CAR $(80 \% / 80 \%)$. At the present time, CAR evaluation is not suitable for diagnostic use in CD.

In summary, this study originally described a blunted CAR on active CD. This subtle dysfunction of the HPA axis may represent a distinct and additional physiopathological phenomenon superimposing the dysregulated cortisol circadian rhythm in this disease.

\section{Declaration of interest}

The authors declare that there is no conflict of interest that could be perceived as prejudicing the impartiality of the research reported.

\section{Funding}

This work was supported by grants from Fundação de Amparo à Pesquisa do Estado de Sao Paulo (FAPESP 07/58365-3; 10/03039-7) and Conselho Nacional de Desenvolvimento Científico e Tecnológico (CNPq 314279/2009-1).

\section{Acknowledgements}

The authors would like to thank the expert technical support of José Roberto da Silva, Lucimara Bueno, and Adriana Rossi. 


\section{References}

1 Hellman L, Nakada F, Curti J, Weitzman ED, Kream J, Roffwarg H, Ellman S, Fukushima DK \& Gallagher TF. Cortisol is secreted episodically by normal man. Journal of Clinical Endocrinology and Metabolism 197030 411-422. (doi:10.1210/jcem-30-4-411)

2 Weitzman ED, Fukushima D, Nogeire C, Roffwarg H, Gallagher TF \& Hellman L. Twenty-four hour pattern of the episodic secretion of cortisol in normal subjects. Journal of Clinical Endocrinology and Metabolism 197133 14-22. (doi:10.1210/jcem-33-1-14)

3 Dickmeis T. Glucocorticoids and the circadian clock. Journal of Endocrinology 2009200 3-22. (doi:10.1677/JOE-08-0415)

4 Kalsbeek A, Palm IF, La Fleur SE, Scheer FA, Perreau-Lenz S, Ruiter M, Kreier F, Cailotto C \& Buijs RM. SCN outputs and the hypothalamic balance of life. Journal of Biological Rhythms 2006 21 458-469. (doi:10.1177/0748730406293854)

5 Krout KE, Kawano J, Mettenleiter TC \& Loewy AD. CNS inputs to the suprachiasmatic nucleus of the rat. Neuroscience $2002 \mathbf{1 1 0}$ 73-92. (doi:10.1016/S0306-4522(01)00551-6)

6 Pruessner JC, Wolf OT, Hellhammer DH, Buske-Kirschbaum A, von Auer K, Jobst S, Kaspers F \& Kirschbaum C. Free cortisol levels after awakening: a reliable biological marker for the assessment of adrenocortical activity. Life Sciences $1997612539-2549$. (doi:10.1016/S0024-3205(97)01008-4)

7 Wilhelm I, Born J, Kudielka BM, Schlotz W \& Wust S. Is the cortisol awakening rise a response to awakening? Psychoneuroendocrinology 200732 358-366. (doi:10.1016/j.psyneuen.2007.01.008)

8 Clow A, Thorn L, Evans P \& Hucklebridge F. The awakening cortisol response: methodological issues and significance. Stress 20047 29-37. (doi:10.1080/10253890410001667205)

9 Edwards S, Evans P, Hucklebridge F \& Clow A. Association between time of awakening and diurnal cortisol secretory activity. Psychoneuroendocrinology $2001 \quad 26$ 613-622. (doi:10.1016/ S0306-4530(01)00015-4)

10 Clow A, Hucklebridge $\mathrm{F} \&$ Thorn L. The cortisol awakening response in context. International Review of Neurobiology 201093 153-175. (doi:10.1016/S0074-7742(10)93007-9).

11 Fries E, Dettenborn L \& Kirschbaum C. The cortisol awakening response (CAR): facts and future directions. International Journal of Psychophysiology 200972 67-73. (doi:10.1016/j.ijpsycho.2008. 03.014)

12 Wust S, Wolf J, Hellhammer DH, Federenko I, Schommer N \& Kirschbaum $\mathrm{C}$. The cortisol awakening response - normal values and confounds. Noise $\mathcal{E}$ Health 20002 79-88.

13 Buchanan TW, Kern S, Allen JS, Tranel D \& Kirschbaum C. Circadian regulation of cortisol after hippocampal damage in humans. Biological Psychiatry 200456 651-656. (doi:10.1016/j. biopsych.2004.08.014)

14 Wolf OT, Fujiwara E, Luwinski G, Kirschbaum C \& Markowitsch HJ. No morning cortisol response in patients with severe global amnesia. Psychoneuroendocrinology $2005 \quad \mathbf{3 0}$ 101-105. (doi:10.1016/j.psyneuen.2004.05.001)

15 Bhagwagar Z, Hafizi S \& Cowen PJ. Increase in concentration of waking salivary cortisol in recovered patients with depression. American Journal of Psychiatry $2003 \mathbf{1 6 0}$ 1890-1891. (doi:10.1176/appi.ajp.160.10.1890)

16 Wirtz PH, von Kanel R, Emini L, Ruedisueli K, Groessbauer S, Maercker A \& Ehlert U. Evidence for altered hypothalamuspituitary-adrenal axis functioning in systemic hypertension: blunted cortisol response to awakening and lower negative feedback sensitivity. Psychoneuroendocrinology 200732 430-436. (doi:10.1016/j.psyneuen.2007.02.006)

17 Steptoe A \& Ussher M. Smoking, cortisol and nicotine. International Journal of Psychophysiology 200659 228-235. (doi:10.1016/j. ijpsycho.2005.10.011)

18 Therrien F, Drapeau V, Lalonde J, Lupien SJ, Beaulieu S, Tremblay A \& Richard D. Awakening cortisol response in lean, obese, and reduced obese individuals: effect of gender and fat distribution. Obesity 200715 377-385. (doi:10.1038/oby.2007.509)
19 Raff H, Raff JL \& Findling JW. Late-night salivary cortisol as a screening test for Cushing's syndrome. Journal of Clinical Endocrinology and Metabolism $1998 \mathbf{8 3} 2681-2686$. (doi:10.1210/jc.83.8.2681)

20 Castro M, Elias PC, Quidute AR, Halah FP \& Moreira AC. Out-patient screening for Cushing's syndrome: the sensitivity of the combination of circadian rhythm and overnight dexamethasone suppression salivary cortisol tests. Journal of Clinical Endocrinology and Metabolism 199984 878-882. (doi:10.1210/ jc. 84.3 .878 )

21 Nieman LK, Biller BM, Findling JW, Newell-Price J, Savage MO, Stewart PM \& Montori VM. The diagnosis of Cushing's syndrome: an Endocrine Society Clinical Practice Guideline. Journal of Clinical Endocrinology and Metabolism 200893 1526-1540. (doi:10.1210/jc.2008-0125)

22 Trainer PJ, Lawrie HS, Verhelst J, Howlett TA, Lowe DG, Grossman AB, Savage MO, Afshar F \& Besser GM. Transsphenoidal resection in Cushing's disease: undetectable serum cortisol as the definition of successful treatment. Clinical Endocrinology 199338 73-78. (doi:10.1111/j.1365-2265.1993.tb00975.x)

23 Rollin GA, Ferreira NP, Junges M, Gross JL \& Czepielewski MA. Dynamics of serum cortisol levels after transsphenoidal surgery in a cohort of patients with Cushing's disease. Journal of Clinical Endocrinology and Metabolism 200489 1131-1139. (doi:10.1210/jc.2003-031170)

24 Santiago LB, Jorge SM \& Moreira AC. Longitudinal evaluation of the development of salivary cortisol circadian rhythm in infancy. Clinical Endocrinology $1996 \mathbf{4 4}$ 157-161. (doi:10.1046/j.13652265.1996.645466.x)

25 Vieira JG, Nakamura OH \& Carvalho VM. Measurement of free urinary cortisol and cortisone using liquid chromatography associated with tandem mass spectrometry method. Arquivos Brasileiros de Endocrinologia e Metabologia 200549 291-298. (doi:10.1590/S0004-27302005000200017)

26 Buysse DJ, Reynolds CF III, Monk TH, Berman SR \& Kupfer DJ. The Pittsburgh Sleep Quality Index: a new instrument for psychiatric practice and research. Psychiatry Research 198928 193-213. (doi:10.1016/0165-1781(89)90047-4)

27 Castro M \& Moreira AC. Screening and diagnosis of Cushing's syndrome. Arquivos Brasileiros de Endocrinologia e Metabologia 200751 1191-1198. (doi:10.1590/S0004-273020070008 $00004)$

28 Carroll T, Raff H \& Findling JW. Late-night salivary cortisol for the diagnosis of Cushing syndrome: a meta-analysis. Endocrine Practice 200915 335-342. (doi:10.4158/EP090230R)

29 DeSantis AS, DiezRoux AV, Hajat S, Golden SH, Jenny NS, Sanchez BN, Shea S \& Seeman TE. Associations of salivary cortisol levels with metabolic syndrome and its components: the multi-ethnic study of atherosclerosis. Journal of Clinical Endocrinology and Metabolism 201196 3493. (doi:10.1210/jc. 2011-0483)

30 Maina G, Bovenzi M, Palmas A, Rossi F \& Filon FL. Psychosocial environment and health: methodological variability of the salivary cortisol measurements. Toxicology Letters $2012 \mathbf{2 1 3} 21-26$. (doi:10.1016/j.toxlet.2011.08.019)

31 Kumari M, Badrick E, Ferrie J, Perski A, Marmot M \& Chandola T. Self-reported sleep duration and sleep disturbance are independently associated with cortisol secretion in the Whitehall II study. Journal of Clinical Endocrinology and Metabolism 200994 4801-4809. (doi:10.1210/jc.2009-0555)

32 Dettenborn L, Rosenloecher F \& Kirschbaum C. No effects of repeated forced wakings during three consecutive nights on morning cortisol awakening responses (CAR): a preliminary study. Psychoneuroendocrinology 200732 915-921. (doi:10.1016/j. psyneuen.2007.06.011)

33 Dahlgren A, Kecklund G, Theorell T \& Akerstedt T. Day-to-day variation in saliva cortisol - relation with sleep, stress and self-rated health. Biological Psychology $2009 \mathbf{8 2} 149-155$. (doi:10.1016/j.biopsycho.2009.07.001)

34 Vreeburg SA, Kruijtzer BP, van Pelt J, van Dyck R, DeRijk RH, Hoogendijk WJ, Smit JH, Zitman FG \& Penninx BW. Associations 
between sociodemographic, sampling and health factors and various salivary cortisol indicators in a large sample without psychopathology. Psychoneuroendocrinology 200934 1109-1120. (doi:10.1016/j.psyneuen.2009.04.024)

35 Burgess N, Maguire EA \& O’Keefe J. The human hippocampus and spatial and episodic memory. Neuron 200235 625-641. (doi:10.1016/S0896-6273(02)00830-9)

36 Herman JP \& Cullinan WE. Neurocircuitry of stress: central control of the hypothalamo-pituitary-adrenocortical axis. Trends in Neuroscience 199720 78-84. (doi:10.1016/S01662236(96)10069-2)

37 Herman JP, Ostrander MM, Mueller NK \& Figueiredo H. Limbic system mechanisms of stress regulation: hypothalamo-pituitaryadrenocortical axis. Progress in Neuro-Psychopharmacology \& Biological Psychiatry 200529 1201-1213. (doi:10.1016/ j.pnpbp.2005.08.006)

38 Jacobson L \& Sapolsky R. The role of the hippocampus in feedback regulation of the hypothalamic-pituitary-adrenocortical axis. Endocrine Reviews 199112 118-134. (doi:10.1210/edrv12-2-118)
39 Starkman MN, Gebarski SS, Berent S \& Schteingart DE. Hippocampal formation volume, memory dysfunction, and cortisol levels in patients with Cushing's syndrome. Biological Psychiatry 199232 756-765. (doi:10.1016/0006-3223(92)90079-F)

40 Resmini E, Santos A, Gómez-Anson B, Vives Y, Pires P, Crespo I, Portella MJ, Juan-Delago M, Barahona MJ \& Webb S. Verbal and visual memory performance and hippocampal volumes, measured by 3-Tesla magnetic resonance imaging, in patients with Cushing's syndrome. Journal of Clinical Endocrinology and Metabolism 2012 97 663-671. (doi:10.1210/jc.2011-2231)

41 Starkman MN, Giordani B, Gebarski SS, Berent S, Schork MA \& Schteingart DE. Decrease in cortisol reverses human hippocampal atrophy following treatment of Cushing's disease. Biological Psychiatry 199946 1595-1602. (doi:10.1016/S0006-3223(99)00203-6)

Received 8 November 2012

Revised version received 1 February 2013

Accepted 7 February 2013 